\title{
MERCADOS IMOBILIÁRIOS EM ÁREAS POBRES: SINGULARIDADES, PARTICULARIDADES E UNIVERSALIDADES ${ }^{1}$
}

\author{
NORMA LACERDA \\ Universidade Federal de Pernambuco
}

\section{Introdução}

Os estudos sobre os mercados informais de solo urbano nas cidades brasileiras e acesso dos pobres ao solo, desenvolvidos no âmbito da Rede Infosolo, no período entre 2005 e 2007, mostram que, a partir da década dę 1990, o mercado informal constitui o principal meio de acesso à moradia. ${ }^{2}$ As análises realizadas foram veiculadas sob a forma de artigos, reunidos no livro intitulado Mercado imobiliário informal, a porta de entrada nas favelas brasileiras (2009), organizado por Pedro Abramo (IPPUR/UFRJ).

A leitura desses artigos levou a inferir-se que o mercado imobiliário de locação em áreas pobres assume uma importante função social nas metrópoles brasileiras. No caso da Região Metropolitana do Recife (RMR), é a principal porta de acesso à moradia. De fato, em 2005, do total dos imóveis pesquisados em quatro áreas pobres - Brasília Teimosa, Mustardinha e Pilar, no Recife, e Passarinho, em Olinda -, 57,9\% haviam sido alugados no período considerado pela pesquisa ${ }^{3}$, e os restantes

\footnotetext{
${ }^{1}$ Este artigo foi desenvolvido no âmbito do Grupo de Estudos sobre o Mercado Fundiário e Imobiliário (GEMFI) do Programa de Pós-graduação em Desenvolvimento Urbano (MDU) da Universidade Federal de Pernambuco (UFPE), mais especificamente na pesquisa sobre o Funcionamento do mercado de habitações em áreas pobres da Região Metropolitana do Recife, contando com o apoio do CNPq.

${ }^{2}$ Foram analisados os mercados informais de habitação nas seguintes metrópoles: Porto Alegre, Florianópolis, São Paulo, Rio de Janeiro, Brasília, Salvador, Recife e Belém.

${ }^{3}$ Esses questionários envolveram todos os imóveis alugados, postos à venda e comprados nos seis meses anteriores ao dia da aplicação de cada um.
} 
$(42,1 \%)$ haviam sido comprados ou estavam à venda. Em Brasília Teimosa, 72\% das transações imobiliárias referiam-se à locação.

Acresce que em todas as cidades pesquisadas, no âmbito da pesquisa Infosolo, o mercado imobiliário em áreas pobres (MIAP) apresenta duas características ou regras gerais de funcionamento: é autorreferenciado, ou seja, é espacialmente atomizado, conformando vários submercados, da mesma forma como ocorre no mercado imobiliário formal e tipificado, nesses submercados, pela prevalência de relações interpessoais diferentemente do mercado imobiliário formal, em que predomina a impessoalidade - mais prolongadas no mercado de aluguel, do que no de compra e venda.

A continuidade das reflexões sobre esse mercado na RMR, aliada à leitura atenta dos mencionados artigos, induziu a questionarmos se as duas referidas normas gerais de funcionamento - presentes em todo mercado imobiliário em áreas pobres - não estariam obscurecendo as particularidades e as singularidades observadas em cada um dos submercados, especialmente no de locação, em que as relações interpessoais perduram durante todo o período do aluguel. Em outros termos: essas relações não seriam dependentes da situação de cada submercado?

$\mathrm{O}$ presente texto objetiva analisar a hipótese de que o mercado imobiliário de locação, em áreas pobres das cidades brasileiras, funciona a partir de normas gerais, ou seja, as que estão presentes em todos os submercados, mas também de normas dependentes das situações, nas quais eles se inserem. Quer isso dizer que as normas gerais ou de caráter universal de funcionamento desse mercado permitem a cada um dos submercados imobiliários em áreas pobres, estruturarem-se por mecanismos próprios, dependentes de suas respectivas situações, às quais os agentes devem-se ajustar. O teste dessa hipótese levou a refletir-se sobre a possibilidade de uma leitura econométrica dos preços realizados, bem como sobre a validade de políticas de regularização fundiária de caráter universal.

${ }^{4} \mathrm{O}$ tipo de análise mais difundido, derivado da teoria da economia urbana, é o de preço hedônico. A sua função matemática relaciona o preço do bem heterogêneo (residência) com as suas características. Considera, portanto, que a residência comporta diversos atributos (infraestrutura e serviços urbanos, proximidade dos postos de trabalho e amenidades positivas, entre outros) e estima o preço marginal de cada atributo, a partir da análise do preço realizado e das respectivas características dos seus atributos. 
Com o intuito de apresentar com clareza as reflexões empreendidas, configurou-se em três partes o presente texto. A primeira apresenta uma discussão acerca de como se deve encarar cientificamente um objeto de estudo - no caso, o mercado imobiliário de aluguel em áreas pobres - com suas particularidades e, mesmo, singularidades. Em outras palavras, discute-se como transitar das singularidades e particularidades à universalidade (pensamento indutivo), ou seja, como observar objetos ou fenômenos, singulares por natureza, com o intuito de identificar relações constantes e gerais (leis ou normas), de sorte que, aplicadas a novos contextos, obtenham-se os resultados já verificados.

A segunda parte expõe as particularidades do mercado imobiliário em áreas pobres (MIAP), isto é, as suas propriedades (qualidades que não lhes podem faltar) no confronto com o mercado formal. Essas particularidades autorizam a consideração de tais mercados como dois diferentes objetos de estudo. Em seguida, realçam-se as diferenças entre o mercado de locação e o de compra e venda nas áreas pobres, o que exige análises diferenciadas, à conta das suas respectivas particularidades. Por fim, destaca como as semelhanças existentes entre os submercados imobiliários, em áreas pobres de uma mesma metrópole, incitaram alguns autores a, equivocadamente, formular certas generalizações, presumindo-as válidas para outras realidades metropolitanas.

Finalmente, a terceira parte mostra a impossibilidade de uma análise econométrica dos preços realizados nesse mercado e assinala o quanto seus submercados, notadamente os de aluguel, encerram algo "indecifrável", uma vez que envolvem relações interpessoais, vivenciadas pelos agentes imobiliários informais em situações que eles mesmos têm de interpretar e ajustar. Essa parte do texto ressalta que, apesar da presença de normas gerais, cada subsistema conforma um caso particular, na medida em que responde a situações diversas, ou seja, a contextos econômicos e sociais diferenciados. Ademais, chama a atenção para os problemas a serem enfrentados por políticas de regularização fundiária, direcionadas a todas as cidades brasileiras, sem levar em consideração as singularidades do mercado imobiliário de locação.

\section{Singularidades, particularidades e universalidades}

Estudar o mercado imobiliário em áreas pobres implica deparar-se com singularidades que despertam inquietações sobre a validade de tentarse generalizar as constatações. Muitas das universalizações formuladas 
sobre os submercados imobiliários em áreas pobres, fundamentadas em algumas realidades, não encontram respaldo quando se tenta aplicá-las a outras realidades. Isso mostra um real problema: o salto da experiência ("empeiria", étimo grego) desses objetos ou fatos do mundo real (apreendidos pela consciência na sua particularidade e, mais precisamente, na sua singularidade) para a ciência ("scientia" ou conhecimento, na versão latina). Nesse sentido, é oportuno relembrar o princípio clássico, segundo o qual "não há ciência do particular", quer dizer, de objetos ou fatos particulares. Dito de outra forma: fazer ciência é transcender, consistentemente, das singularidades e particularidades das observações à universalidade das formulações teóricas.

Na realidade, como ensina o filósofo Lahr (1945), se a ciência tivesse por objeto o particular e o singular, ela

deveria formular tantas leis e definições, quantos são os indivíduos e casos particulares - tarefa absurda, por ser impossível definir um só deles. É impossível encerrar numa definição, formular numa lei esta infinidade de pormenores e circunstâncias particulares que constituem o ser ou o fato individual. (Lahr, 1945a, p. 339)

Sendo assim, prossegue o filósofo, indagando:

Depois, qual seria a utilidade de semelhante conhecimento? De fato, nada se pode concluir e nada se pode tirar, a não ser o próprio fato (...) Notemos que neste fluxo e refluxo entre indivíduos e fatos que mudam e se renovam incessantemente há algo que não muda, que não passa: são as relações; relações entre as formas que existem nos indivíduos da mesma espécie; relações entre as circunstâncias que se sucedem sempre do mesmo modo nos fenômenos da mesma natureza; relações entre as grandezas, entre as verdades. (Lahr, 1945b, p. 340)

Essas relações - conforme o mesmo autor - constituem o tipo, a lei, o princípio, representando o que há de uno na multiplicidade, de simples, na complexidade, de idêntico e estável, nessa variedade e mobilidade. Afinal, o indivíduo morre, mas a espécie é constante; o fato muda, mas a lei é constante; as aplicações e as consequências são variáveis e contingentes, mas o princípio é imutável e necessário. "Libertar a lei dos fatos, subir dos indivíduos ao gênero, das aplicações ao princípio, eis o 
verdadeiro objeto da ciência" (Lahr, 1945c, p. 340).

Sendo assim, o interesse maior reside no processo indutivo, cujos procedimentos (método) de análise e síntese exigem a passagem das partes constituintes ao todo que as explica e determina. Tal método demanda, portanto, a identificação de regularidades e constância universais que definam o modo de ser e de comportar-se do objeto. ${ }^{5}$ Não se pretende com esta explanação - como poderia parecer à primeira vista - ensinar ao leitor o que é processo indutivo e muito menos o que é ciência. Intenta-se apenas chamar a atenção para os riscos da generalização indiscriminada de resultados não aplicáveis em certas realidades.

No caso em estudo, adotar o método indutivo requer apreender os submercados imobiliários de aluguel em áreas pobres - particulares e singulares, por natureza - por meio da identificação dos seus respectivos e distintos $^{6}$ mecanismos de funcionamento. A partir daí, extrair com segurança as relações constantes e gerais que os presidem, ou seja, aquelas que não mudam. Isso deve ser realizado com o cuidado de não cair na armadilha das generalizações apressadas, que terminam por esconder ou não evidenciar a própria natureza do fenômeno estudado: a existência de particularidades e singularidades.

Particular (do latim particularis) refere-se a uma parte inerente a uma dada realidade e distinta das demais à conta das suas propriedades (ou qualidades indissociáveis e obrigatoriamente presentes no objeto considerado). Corresponde a uma parcela ou subconjunto de um todo.

Singular (também do latim, singularis) significa único. De modo que, em geral, particularidades reúnem singularidades. São dois termos não raro utilizados como sinônimos, muito embora guardem significados bem

5 Marilena Chauí (1997, p. 278), ao tecer comentários sobre a lógica que rege o pensamento científico, adverte que a ciência contemporânea se funda na separação do sujeito e objeto do conhecimento; na ideia de método, como um conjunto de regras, normas e procedimentos gerais; nas operações de análise e síntese; na ideia de lei do fenômeno, isto é, de regularidades e constâncias universais e necessárias; no uso de instrumentos tecnológicos e na criação de uma linguagem específica.

${ }^{6}$ Guareschi (1998) ressalta que Henrique Dussel (1977), ao discutir a questão da ética, mostra como o "outro" pode estar presente no "mesmo", de duas maneiras: como diferente e distinto. Diferente vem do latim dis (divisão) e ferre (levar com violência, arrastar). O diferente é arrastado da sua identidade original e coloca-se como oposto. Distinto também vem do latim dis (divisão) e tingere (tingir, pintar), sem, no entanto, ser arrastado para fora, mas possuindo a sua identidade e estabelecendo com "o mesmo" relação de diálogo. 
diferenciados.

Tais esclarecimentos são importantes por duas razões. Em primeiro lugar, porque se devem ressaltar as particularidades que, presentes no mercado imobiliário em áreas pobres, o distinguem do mercado imobiliário formal. Com efeito, elas é que autorizam a reconhecê-lo como uma totalidade e, portanto, como um objeto de estudo.

Em segundo lugar, porque, diante do reconhecimento de particularidades que garantem o funcionamento desse mercado em determinadas circunstâncias (ou situações), importa indagar até que ponto elas comportam singularidades. É que a singularidade de uma situação vivenciada pelos agentes do mercado analisado impede qualquer generalização, a menos que observações bem controladas atestem que ela não é eventual ou episódica, mas sim inerente à estrutura do objeto considerado e, portanto, presente em todos os casos em que essa estrutura se replique.

No entanto, como se verá adiante, alguns estudos sobre o mercado imobiliário informal têm, inadvertidamente, generalizado algumas singularidades, transformando-as em "leis" ou "normas", que estariam presentes em qualquer mercado imobiliário informal. Semelhantes generalizações, além de permitirem questionar-se o próprio caráter científico desses estudos, acabam por encobrir as singularidades do objeto de estudo, o mercado imobiliário informal, ao invés de realçá-las. Tal encobrimento, segundo a hipótese formulada, compromete a eficácia das políticas de regularização fundiária de pretenso caráter universal.

\section{Propriedades dos mercados imobiliários formais e em áreas pobres}

O mercado imobiliário formal e o de áreas pobres, embora apresentem similitudes, são marcados por propriedades que os diferenciam e, consequentemente, os transformam em diferentes - na rigorosa acepção do termo - objetos de investigação.

Os estudos realizados pela autora do presente texto (Lacerda, 1993, 2009) indicam que, no mercado imobiliário formal, as decisões dos compradores e vendedores ou dos locadores e inquilinos são pautadas por um modelo de concorrência monopolista. Edward Chamberlain foi, em 1933, um dos primeiros economistas a levantar a hipótese da concorrência perfeita, na tentativa de identificar o modelo a partir do qual os agentes do mercado fundiário tomam suas decisões. Para ele, o mercado fundiário 
existe em condições bem peculiares. Daí preconizar que a renda do solo urbano é puramente monopolística, colocando no centro da análise a noção de diferenciação espacial.

Marx considera que, no caso urbano, a renda de monopólio é a mais explicativa dos preços realizados no mercado. Entretanto, ele não qualifica o tipo de monopólio, como o faz Chamberlain, para quem o mercado do solo urbano comporta elementos de concorrência perfeita, na medida em que nele atuam vários vendedores e compradores, e, ao mesmo tempo, elementos de monopólio, decorrentes da situação peculiar do terreno na estrutura urbana. Daí a denominação de concorrência monopolística (Lacerda, 1993).

Leftwich retoma essa tese e lhe dá uma definição precisa: "No mercado de concorrência monopolística há muitos vendedores de um produto particular e o produto de cada vendedor é, de certa maneira, diferenciado daquele dos outros vendedores" (Leftwich, 1979a, p. 279). Para ele, essa modalidade de mercado fornece uma descrição melhor das indústrias competitivas, cujos produtos são diferenciados.

No mercado formal de habitação, existem muitos vendedores (empresas) e muitos compradores (usuários), no caso das transações de compra e venda, e muitos locadores (proprietários de imóveis) e locatários (usuários), no caso de aluguel. Tanto um quanto o outro caracterizam-se por uma situação de concorrência perfeita. Acontece que os produtos são diversos no que se refere ao tipo de domicílio (casa, apartamento), número de cômodos, material de construção das paredes, tipo de piso e coberta, além, evidentemente, da localização. O fato de os produtos serem altamente diferenciados caracteriza uma situação de monopólio.

Ora, quantos vendedores devem existir para assegurar-se a classificação de concorrência monopolística? Segundo Leftwich

[...] essas questões não podem ter respostas objetivas em termos numéricos. Quando o número de vendedores é suficiente para que as ações de um não tenham efeito sobre as ações dos demais, e que as ações desses últimos não o afetem, a indústria está em situação de concorrência monopolística. (Leftwich 1979b, p. 279)

Para ele, a análise é muito semelhante à da concorrência perfeita, sendo que a diferenciação dos produtos vai conferir uma função importante da demanda na fixação dos preços. 
Um dos pontos fundamentais do modelo de concorrência monopolística reside, exatamente, nas condições da demanda. A diferenciação dos produtos induz os consumidores a escolherem o produto de um vendedor, o que confere à oferta a capacidade de exercer certo controle sobre os preços. Isso significa que diferentes vendedores obterão preços diversos, segundo o julgamento dos consumidores, em relação às qualidades comparativas dos produtos diferenciados (Lacerda, 1993).

De acordo com Vincent (1986, p. 15), a concorrência monopolística recorre à elasticidade cruzada da demanda, isto é, à elasticidade de um bem substituto, em relação ao preço de um bem original, "princípio de substituição estrita", o que dá uma boa representação das situações concretas, porquanto uma pessoa que procura comprar um imóvel não se decide jamais sem antes comparar várias outros, ainda que pouco diferentes entre si.

Isso não significa que os imóveis colocados à venda ou alugados no mercado formal incorporem sempre elementos monopolísticos e que, inevitavelmente, a taxa de satisfação do vendedor ou locador seja mais importante que a média, o que conduziria à conclusão de que a atividade imobiliária formal tem uma taxa generalizada de lucro acima da média. $\mathrm{Na}$ realidade, o que acontece é que, em certas localizações, os preços fundiários e imobiliários comportam elementos de monopólio e, em outras, não. Nestas últimas, os promotores imobiliários entram em concorrência e os preços de mercado podem gravitar em torno dos preços de produção (Lacerda, 1993).

Não sem razão, o mercado imobiliário formal de uma determinada cidade é formado por diversos submercados com preços distintos de acordo com a sua respectiva localização e seus atributos em termos de infraestrutura, equipamentos e serviços urbanos e de significado (status, poder, prestígio). Tais características viabilizariam uma análise econométrica dos preços praticados nesse mercado, como a realizada pela autora do presente texto em outro trabalho (Lacerda, 1993).

Ademais, nesse mercado, atuam, direta e indiretamente, diversos outros agentes, além de compradores e vendedores, locadores e inquilinos. Diretamente, atuam os proprietários dos terrenos; escritórios de arquitetura e engenharia; detentores de capitais financeiros a quem cabe, na maioria das vezes, garantir os recursos necessários à produção e à comercialização de bens imobiliários, podendo advir do Estado ou do setor privado; corretores de imóveis, que intermediam a circulação desses bens e fiadores, a quem cabe a responsabilidade, em última instância, dos pagamentos das 
prestações relativas às transações de compra e venda ou às mensalidades, no caso do aluguel. Indiretamente, atuam: o Estado, por meio de políticas macroeconômicas (que definem níveis salariais e taxas de juros), de legislações urbanísticas e do provimento de infraestruturas, equipamentos e serviços urbanos. Acresce que esse mercado necessita de instituições formais e, com elas, de um aparato legal para garantir que os acordos sejam respeitados pelas partes envolvidas.

No mercado imobiliário em áreas pobres, poder-se-ia partir do pressuposto de que também funciona a partir de uma situação de concorrência monopolística. Os produtos transacionados, como mostra a pesquisa em rede, são bastante heterogêneos. Vários vendedores e locadores atuam nesse mercado, em quantidade proporcionalmente maior do que no mercado formal, porquanto cada empresa incorporadora lança um número razoável de produtos imobiliários de modo que, muitas vezes, um vendedor (ou locador) é proprietário de diversos imóveis. A quantidade de usuários pode ser tão significativa quanto no mercado formal. Funciona, também, a partir de submercados muitas vezes espacialmente atomizados e autorreferenciados. A cada um deles corresponde uma área pobre. Isso significa que os agentes de um determinado submercado para fixarem os preços não se baseiam em outras localidades, mas, sim, nos preços históricos praticados no entorno dos imóveis. Esses preços são estimados. Geralmente, porém, não são realizados na medida em que locadores e inquilinos os ajustam conforme a situação por eles vivenciada.

Acrescente-se que a produção de imóveis novos informais, sobretudo nas áreas pobres consolidadas, é significativamente reduzida quando comparada à do mercado formal. Quase sempre ocorre por meio do fracionamento do lote ocupado e/ou da subdivisão da moradia, assim como por verticalizações e/ou "puxadas" a partir da edificação original. Diferindo do que se dá no mercado formal, como bem admite Abramo (2009), a oferta nos assentamentos consolidados é praticamente inelástica frente à demanda. Mesmo assim, o mercado imobiliário informal tem sido responsável por uma ocupação intensiva das áreas pobres consolidadas, como se verá mais adiante. Isso demonstra que é preferível estar integrado a uma determinada comunidade e articulado com o seu entorno a que morar na periferia urbana. Tal situação, com certeza, contribui para que os preços por metro quadrado nessas áreas sejam, algumas vezes, superiores quando comparados aos realizados no mercado formal.

Ademais, existem distinções socioespaciais no interior de cada área pobre, como será ilustrado adiante. Isso poderia conferir um poder de monopólio relativo àquelas localizações mais bem dotadas de 
infraestruturas, bens e serviços urbanos. Esse monopólio decorreria, em última instância, do poder de compra da demanda. Era essa, aliás, uma hipótese defendida em artigo anterior da autora do presente texto (Lacerda, 2009). Contudo, o prosseguimento da pesquisa levou a negá-la, à conta da impossibilidade de uma análise econométrica dos preços imobiliários nas áreas pobres informais como resultado das suas particularidades e, mais precisamente, das suas singularidades, analisadas a seguir.

Os estudos empreendidos, no âmbito da Região Metropolitana, mostram que, no mercado imobiliário em áreas pobres, as transações são realizadas, envolvendo diretamente dois agentes: comprador e vendedor, no caso do de compra e venda, e locador e inquilino, no caso do de locação. Pelo lado da oferta, os "proprietários" (vendedores ou locadores) são os ocupantes dos imóveis construídos, à revelia da lei, com seus próprios recursos. Pelo lado da demanda, os rendimentos dos compradores são, muitas vezes, informais, não os autorizando, no caso de compra e venda, a solicitar financiamento junto às instituições financeiras formais. Tampouco possuem bens a serem oferecidos como garantia contratual de empréstimo aos agentes financeiros. Eventuais financiamentos ou empréstimos acontecem a partir de bases informais (entre amigos, parentes etc.).

Como a presença de corretores, oneraria o preço final de compra e venda ou de aluguel, e esse tipo de agente não atua no mercado imobiliário informal - pelo menos na RMR - intermediando as relações mercantis.

A atuação do Estado resume-se praticamente na legislação e na promoção de intervenções urbanísticas: a legislação demarca, no máximo, as áreas pobres como de interesse social, sem definição de parâmetros de uso e ocupação do solo urbano; a promoção de intervenções urbanísticas participa do processo de diferenciação socioespacial no interior de cada área pobre. No mais, o Estado não atua por meio de um aparato legal capaz de assegurar os compromissos convencionados durante as transações imobiliárias.

$\mathrm{Na}$ ausência desse aparato legal (Abramo, 2009) como elemento de garantia das relações contratuais surgem instituições informais de mediação, permitindo que os contratos implícitos, convencionados entre as partes, sejam respeitados, em termos intertemporais e intergerenciais, o que inclui mecanismos coercitivos, na hipótese de rompimento contratual por uma das partes.

Para Abramo (2009), a mediação institucional assume a função de um terceiro ator, cuja figura é reconhecida como "autoridade local" Trata- 
se de mediadora nos conflitos incidentes nas comunidades populares como uma "espécie de fiadora." Essa "autoridade", segundo o referido autor, resulta de processos históricos locais que a instituem como tal, podendo ser de natureza religiosa, étnica, cultural, política ou, até mesmo, decorrente da violência e do controle pela força, como se têm mostrado algumas pesquisas empíricas sobre o mercado imobiliário em áreas pobres na América Latina.

De acordo ainda com Abramo (2009), uma base importante da garantia do funcionamento do mercado imobiliário informal reside nas relações de confiança-lealdade. Isso eliminaria a impessoalidade nas relações, uma das marcas do mercado imobiliário formal. Ocorre que, se os comportamentos dos indivíduos fundamentam-se em relações de confiança-lealdade, que necessidade haveria de uma "autoridade local"?

Em nenhuma das localidades pesquisadas na RMR, constatou-se a figura de um mediador com função de "fiador". Na ausência de "autoridades locais", impõem-se as relações de confiança-lealdade sob a forma de convenções, que garantem o funcionamento do mercado imobiliário em áreas pobres. Nessas áreas, sobretudo no mercado de locação (diversamente do de compra e venda), as relações diretas entre locadores e locatários persistem por certo tempo. E a tendência é que elas se estreitem ao longo das oportunidades de convivência.

Essa constatação permite afirmar que a presença de uma "autoridade local" configura uma particularidade presente nos mercados imobiliários de algumas metrópoles, a exemplo do Rio de Janeiro e de São Paulo, não constituindo, porém, uma "lei" de caráter universal, nem mesmo uma condição sine qua non para o funcionamento do mercado imobiliário em áreas pobres. Ele funciona, em determinadas situações, como se verá adiante, sem a presença de "fiadores" ou de "autoridades locais."

$\mathrm{Na}$ verdade, as relações interpessoais constituem um princípio universal presente no mercado imobiliário em áreas pobres das cidades brasileiras, diferenciando-o (no sentido preciso do termo ${ }^{8}$ ) do mercado imobiliário formal, em que a lei constitui um elemento de garantia das relações contratuais. Nesse último, as relações entre os principais agentes produtores e consumidores - assumem um caráter impessoal, sendo a

\footnotetext{
${ }^{7}$ Reflexões sobre esse mesmo questionamento foram apresentadas no artigo Coordenação do mercado imobiliário de aluguel em áreas pobres: primeira aproximação à luz da teoria das convenções (2011, no prelo).

${ }^{8}$ Ver nota de rodapé $n^{\circ} 6$.
} 
compra e a venda intermediadas por outros agentes (corretores de imóveis) e asseguradas mediante contratos legais.

Contudo, são exatamente as relações interpessoais que dependem da situação dos submercados imobiliários em áreas pobres. Em outros termos, os agentes - compradores e vendedores e locadores e inquilinos - têm de interpretar a situação e ajustar-se a ela. Daí, decorrem as singularidades presentes em cada um desses submercados - com implicações nos preços praticados e no conteúdo das políticas de regularização fundiária - , bem como a impossibilidade de uma análise econométrica dos referidos preços.

\section{Preços realizados no mercado imobiliário de locação em áreas pobres e singularidades das relações interpessoais}

Com o intuito de mostrar a impossibilidade de uma análise econométrica dos preços realizados no mercado imobiliário de locação, na Região Metropolitana do Recife, foram escolhidas duas áreas (Ilustração 1): Brasília Teimosa, no Recife, e Tabatinga, em Camaragibe. É que tais áreas apresentam situações distintas quanto à topografia, localização (face ao centro do Recife), provimento de infraestruturas e situação institucional (Zonas Especiais de Interesse Social - Zeis, ou não).

Brasília Teimosa ${ }^{9}$ corresponde a uma área consolidada próxima do Centro do Recife e do valorizado Bairro de Boa Viagem, e foi instituída como Zeis em 1983 pela Lei de Uso e Ocupação do Solo do Recife. Os dados do Censo Demográfico do IBGE indicam que, em 2010, esse bairro abrigava 5.464 domićlios permanentes, sendo que $20,6 \%$ deles eram alugados. Quanto a Tabatinga, trata-se de bairro pobre não consolidado, situado na franja rural-urbana da metrópole recifense, mais precisamente no município de Camaragibe, limítrofe ao do Recife. Segundo a mesma fonte de dados, essa localidade abrigava, em 2010, 4.286 domicílios. Desses, 12,3\% eram alugados.

\footnotetext{
${ }^{9}$ Nessa área, foram aplicados, em 2005, 139 questionários junto aos inquilinos que haviam alugado seus domicílios nos últimos seis meses, contados a partir da data de aplicação do questionário.
} 


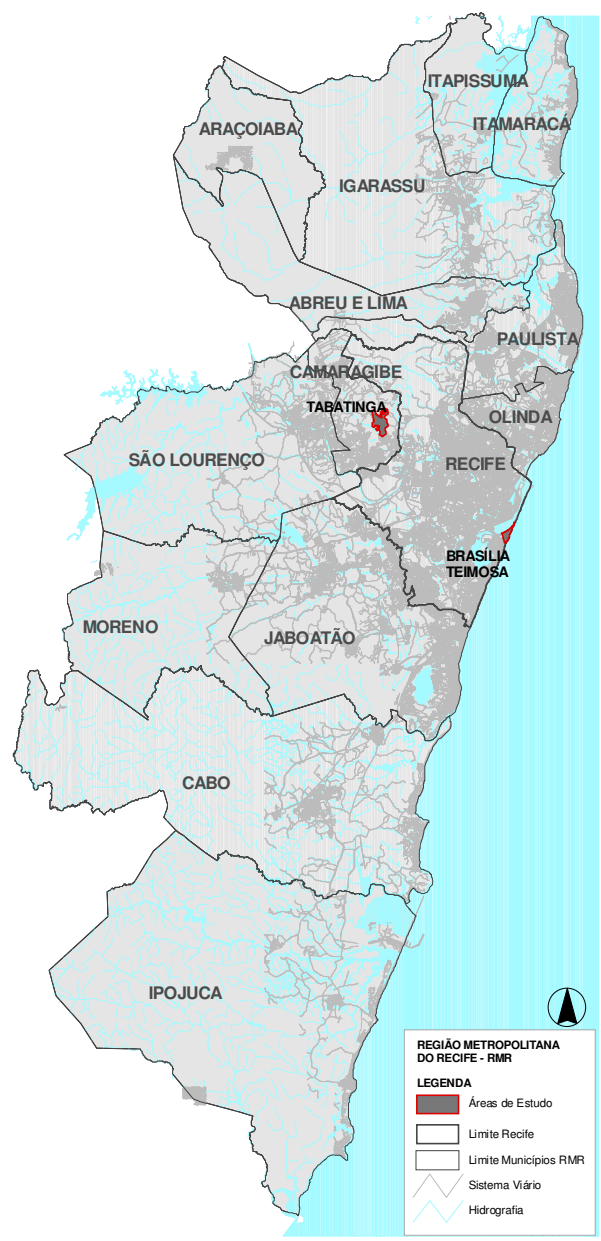

Ilustração 1 - Região Metropolitana do Recife Localização das áreas pesquisadas

A Tabela 1 mostra a evolução dos domicílios de aluguel nessas duas localidades no período de 1991 a 2010. No que se refere a Brasília Teimosa, chamam a atenção os dados relativos ao período de 2000 a 2010, quando a quantidade desses domicílios duplicou, passando de 610 para 1.223. Esse crescimento foi bem mais expressivo, do que o relativo ao período de 1991 a 2000 , quando houve um aumento de $48,42 \%$. 
Tabela 1

Evolução dos domicílios particulares permanentes alugados 1991, 2000 e 2010

\begin{tabular}{|l|r|r|r|r|r|r|r|}
\hline \multirow{2}{*}{ Localidades } & \multicolumn{3}{|c|}{ Domicílios alugados } & \multicolumn{4}{c|}{ Crescimento } \\
\cline { 2 - 8 } & \multirow{2}{*}{1991} & \multirow{2}{*}{2000} & \multirow{2}{*}{2010} & \multicolumn{2}{|c|}{$2000 / 1991$} & \multicolumn{2}{c|}{$2010 / 2000$} \\
\cline { 5 - 8 } & & & & V. Abs. & \% & V. Abs. & \multicolumn{1}{c|}{$\%$} \\
\hline Brasília Teimosa & 411 & 610 & 1223 & 199 & 48,42 & 613 & 100,49 \\
\hline Tabatinga & 237 & 300 & 486 & 63 & 26,58 & 186 & 62,00 \\
\hline
\end{tabular}

Fonte: IBGE, Censos Demográficos de 1991, 2000 e 2010.

Provavelmente esse significativo acréscimo deveu-se à urbanização da sua orla marítima, ocupada por palafitas que se projetavam no mar. Parte da população foi relocada para um conjunto habitacional, situado no bairro do Cordeiro, no Recife, relativamente distante de Brasília Teimosa. Passando a não mais contar com externalidades de vizinhança e a morar mais longe dos locais de trabalho, algumas famílias retornaram para esse bairro, alugando domicílios.

Comparado com o de Brasília Teimosa - área central e consolidada o mercado de locação em Tabatinga evoluiu em ritmo mais lento. No período de 1991 a 2000, cresceu 26,58\% e, no seguinte (de 2000 a 2010), $62 \%$. Nesse bairro, ainda existem áreas a serem ilegalmente ocupadas. Ademais, não conheceu processos de relocação nos termos vivenciados por Brasília Teimosa.

Os dados apresentados confirmam, uma vez mais, que o mercado de locação em áreas pobres tem cumprido importante função social ao permitir à população de menor poder aquisitivo o acesso à moradia. Ao mesmo tempo, confirmam que as políticas habitacionais até então implementadas ainda não foram suficientes para atingir essa faixa populacional (Lacerda, 2010).

Para mostrar a inviabilidade de uma análise econométrica, ou seja, de uma modelagem matemática que estabeleça uma relação entre as variáveis físico-espaciais e os preços de locação, foi necessário, inicialmente, elaborar uma representação de Brasília Teimosa e Tabatinga na escala de seus setores censitários. Preparou-se, então, um mapa temático, a partir do método de quartil, de modo a agrupar os valores de um Indicador Domiciliar (ID) em 5 classes: muito baixa, baixa, regular, alta e muito alta. O ID calculado tomou por base o Censo Demográfico de 2010. Ele combina variáveis relacionadas aos aspectos físicos dos domicílios nas 
duas localidades em pauta, e corresponde à média aritmética simples do Índice de Saneamento (composto por outros três conjuntos de subindicadores: Abastecimento de Água, Destino de Esgotos e Destino do Lixo); do Índice de Tipologia Domiciliar; e do Índice de Condições de Ocupação.

Ressalte-se que esse indicador compõe o Índice de Habitabilidade (IH) desenvolvido por Mauro Normando de Barros Filho (2006). O IH é um sistema de indicadores que objetiva capturar as características de elementos físicos (domicílios) e sociais (pessoas) da estrutura intraurbana, considerando variáveis do Censo Demográfico. Assim, o IH compreende dois conjuntos de indicadores: o Domiciliar (ID) e o Populacional (IP). Esse último refere-se às condições de renda, educação e longevidade da população. Matematicamente, o Indicador de Habitabilidade (IH) é descrito pela média aritmética simples dos Indicadores Domiciliar (ID) e Populacional (IP). Por sua vez, o IP é a média aritmética simples do Índice de Renda (RENDA), do Índice de Educação (EDUCA) e do Índice de Longevidade (LONGE). Para o presente trabalho, foram consideradas variáveis por setor censitário do Censo de 2010. Entretanto, como ainda não foram disponibilizadas todas as variáveis necessárias para a construção do IP, optou-se por apresentar o ID pelos setores censitários que compõem as áreas em estudo e sintetizam as características referentes às condições físico-ambientais mais próximas do período da pesquisa de campo. A Ilustração 2 mostra os resultados obtidos.

Os valores dos Índices Domiciliares dos setores censitários estão representados em tons de azul. Quanto mais escuro o tom, maior a condição de habitabilidade da moradia. Pode-se inferir que, de modo geral, as condições domiciliares de Brasília Teimosa não estão relacionadas nem com a proximidade dos setores, em relação ao entorno formal, nem com as orlas fluvial e marítima. A Ilustração 2 também destaca os preços de aluguel da habitação por metro quadrado. Salta aos olhos a não correspondência entre os preços de aluguel e os índices domiciliares. 


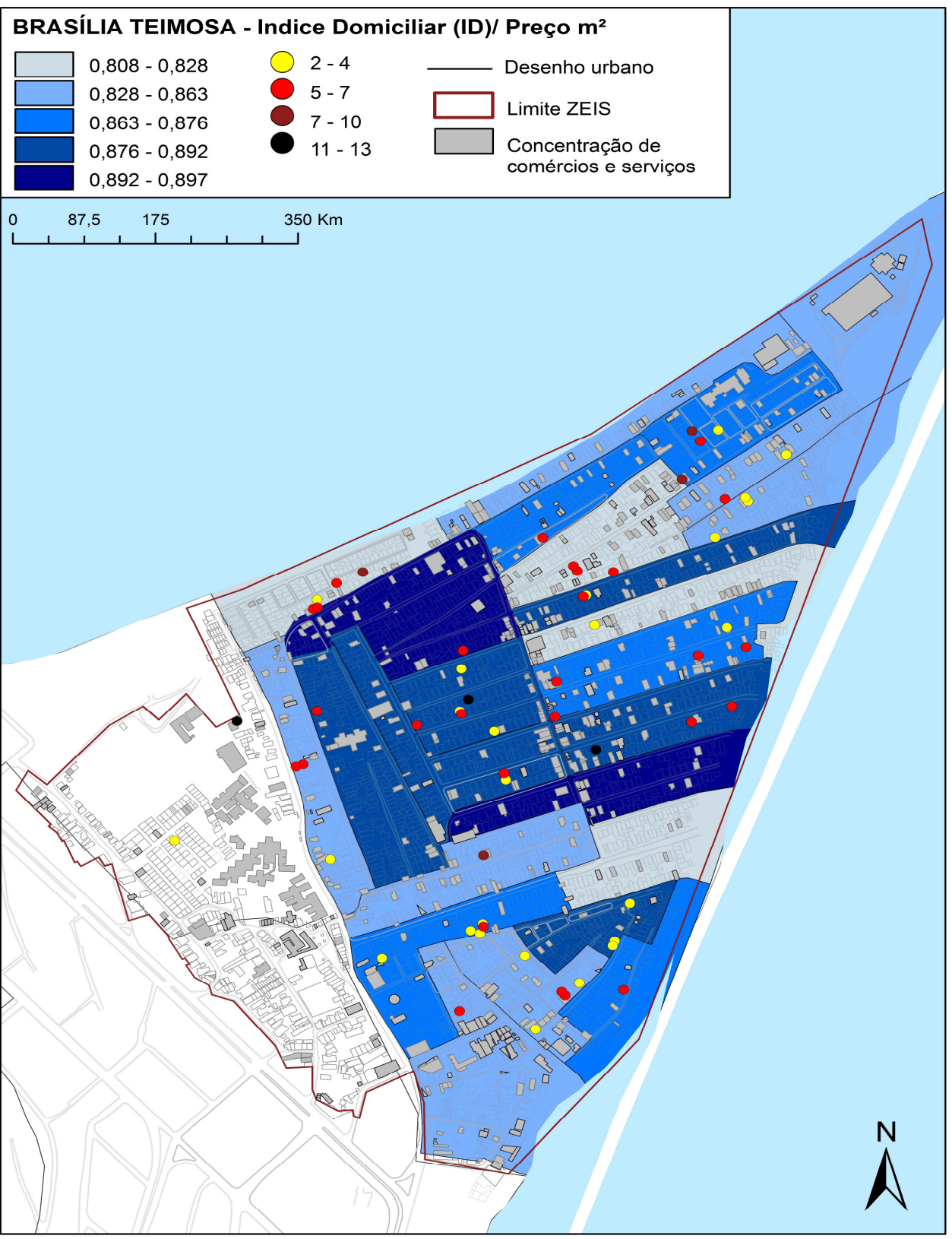

Ilustração 2 - Brasília Teimosa

Índices Domiciliares, preços de aluguel e distribuição espacial dos usos Fontes: IBGE, 2010 e pesquisas de campo 2003 e 2005. 
Essa Ilustração evidencia que esses preços também não guardam relação com a estruturação espacial das atividades de comércio e de serviços. Dito de outra forma, não existe uma relação direta entre o uso do solo, mais precisamente entre a localização dessas atividades, e os preços de locação realizados em Brasília Teimosa. Significa isso que o fator locacional - com todas as suas variáveis de acessibilidade às infraestruturas, aos serviços e aos bens, estruturados no interior de cada um dos assentamentos informais - e os atributos relativos aos aspectos físicos dos domić́lios não explicam os preços praticados no mercado de aluguel. Evidentemente, isso inviabiliza qualquer tentativa de modelagem matemática desses preços.

No caso de Tabatinga, a análise da Ilustração 3 conduzem às mesmas conclusões, quais sejam: os fatores locacionais, no interior dessa localidade, e as condições físicas dos domicílios não explicam os preços realizados no mercado de locação, inviabilizando uma modelagem matemática de tais preços.

Dessa forma, para elucidar os preços realizados no mercado imobiliário de locação, resta considerar as relações interpessoais dos agentes desse mercado. Tais relações foram analisadas no livro Mercado imobiliário em áreas pobres: uma primeira aproximação à luz da Teoria das Convenções ${ }^{10}$ (Lacerda, 2011). Essa Teoria forneceu os aportes necessários para entender-se como e por que - em um mercado, cujas circunstâncias são marcadas pela pobreza, e as contingências (de atrasos no pagamento, inadimplência etc.) o caracterizam - é a convenção confiançalealdade que coordena os atores, pelo menos no caso da metrópole recifense: convenção que dispensa instituições informais (cujo objetivo é garantir que os compromissos assumidos sejam respeitados) e é capaz de afastar a violência (quando esses acordos são violados, por inadimplência, atrasos etc.).

${ }^{10}$ Sobre essa Teoria, além do aludido artigo, ver: De la justification - les économies de la grandeur (BOLTANSKI, L.; THÉVENOT, 1991); Théorie des conventions (BATIFOULIER, 2001); Instituitions et économie des conventions ( BESSY, C.; FAVEREAU, 2003); L'action au pluriel - sociologie des regimes d'engagement (THÉVENOT, L. 2006). 


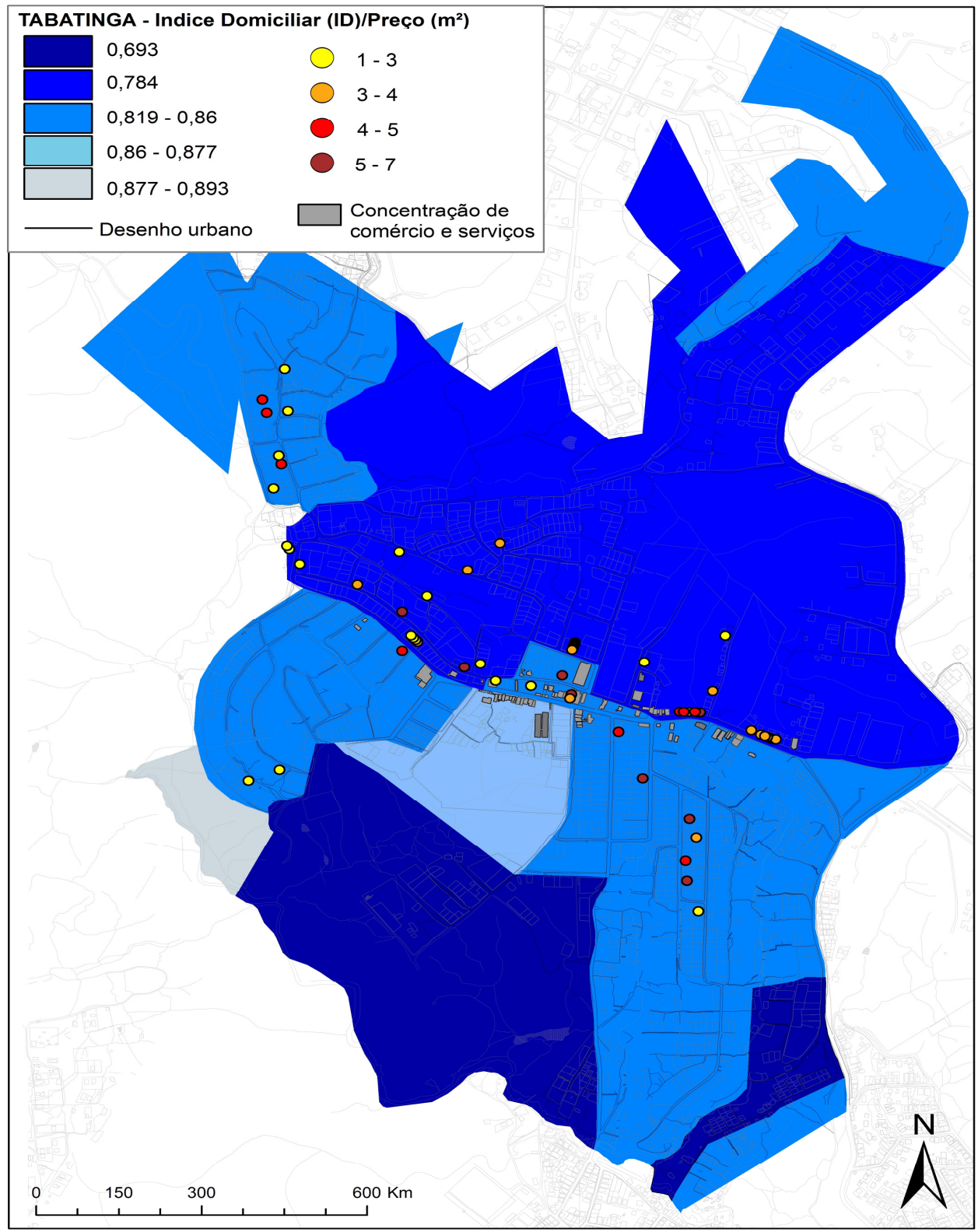

Ilustração 3 - Tabatinga Índices Domiciliares, preços de aluguel e distribuição espacial dos usos Fontes: IBGE, 2010 e pesquisa de campo 2011. 
Em última análise,

Quaisquer que sejam os compromissos assumidos (verbais ou formalizados) entre locadores e inquilinos, as obrigações não os dispensam de interpretação, pois os acordos não podem ser aplicados mecanicamente. Afinal, a interpretação não tem sentido, senão quando os acordos são incompletos, sendo necessário completá-los conforme a situação. Ora, os locadores, diante do perfil socioeconômico dos inquilinos, não teriam motivos, em princípio, para confiar em que eles cumprirão os acordos firmados. Os locatários, por sua vez, ante suas próprias limitações de existência, também não teriam condições reais, em princípio, de assumir lealdade face ao acordado. Aí está o cerne da questão. De antemão, eles estão conscientes de que têm de ajustar-se à situação, ou seja, ao desenrolar dos acontecimentos (perda do emprego, trocas não-realizadas etc.).

(Lacerda, 2011a, p.55).

Nesse cenário, uma atitude objetiva e calculada dos agentes perde qualquer sentido. A atenção dos locadores desloca-se dos preços de mercado, das datas de pagamento, enfim das obrigações pré-estabelecidas para as necessidades e intenções dos locatários, como a de "pagar quando puderem". A atenção destes últimos é, quase sempre, deslocada dos compromissos assumidos à conta das dificuldades de sobrevivência. Honrá-los, porém, é uma questão de tempo, de modo que o equilíbrio do mercado estabelece-se fundamentado na convenção confiança-lealdade.

Acresce que, no mercado imobiliário em áreas pobres (MIAP), é

(...) inócuo procurar saber o fundamento da confiançalealdade. Não há condições reais, na maioria das vezes, da sua efetivação. Por isso mesmo, essa base é totalmente arbitrária, apesar de racional segui-la, com o objetivo de coordenar-se. Não se sabe de onde veio esse fundamento. Trata-se de uma escolha dentre outras. Por isso, constitui uma convenção e, como tal, tem um caráter normativo, coordenando o mercado de locação em áreas pobres. Ademais, garante a existência e o funcionamento desse mercado. Diante das incertezas inerentes ao MIAP, a convenção confiança-lealdade faculta uma sensação de certeza (ou segurança), que facilita as transações econômicas. (Lacerda, 2011b, p. 56). 
Tal sensação revela-se imprescindível para o funcionamento desse mercado, particularmente em determinadas situações, como é o caso de Brasília Teimosa onde 49,60\% do total das famílias de inquilinos recebem até um salário mínimo e 55,07\% deles comprometem mais de $51 \%$ dos seus rendimentos com o aluguel. Aí, não se percebem condições reais de efetivação da convenção confiança-lealdade. Além disso, os locadores, como destaca o referido estudo, são quase tão pobres quanto os inquilinos (38,2\% do total recebem até 2 salários mínimos e 81,13\% dispõem de apenas um domicílio alugado) e muitos deles moram na mesma localidade (82,2\% do total), sendo, algumas vezes, vizinhos e, portanto, mantendo laços de proximidade.

Soma-se a tudo isso o fato de tratar-se de uma mercadoria de que não se pode prescindir - a habitação. Tantas particularidades afastam qualquer possibilidade de os preços de aluguel nas áreas pobres serem fixados a partir de um modelo de concorrência perfeita, que pressupõe um cálculo econômico, no qual o fator localização e o poder aquisitivo da demanda assumem funções preponderantes. Significa isso que "não convence o argumento de que o preço do aluguel, realizado no mercado imobiliário informal de locação, coordenaria a ação dos seus agentes." (Lacerda, 2011c, p. 56).

Por outro lado, as peculiaridades observadas nesse mercado clamam por uma atenção especial do setor público, quando se trata da implementação de políticas de regularização fundiária em determinada localidade. Muitos dos processos em curso, como os implantados e em implantação no Recife, deparam-se com submercados de locação em plena expansão e em situações bastante diversas. Regular-se-ia, então, em nome dos locadores ou dos locatários? Evidentemente, deveria ser em nome do inquilino. Mas o Estado vai desamparar os locadores? E se eles forem quase tão pobres, quanto os inquilinos? Frente ao impasse, a solução até o presente encontrada pelo setor público tem sido a não regularização das casas de aluguel, o que acaba adiando a solução habitacional de parcela importante da população de baixa renda.

\section{Conclusões}

O mercado imobiliário informal tem-se apresentado na atualidade tanto no Brasil quanto na América Latina em geral como a principal forma de acesso das populações de baixa renda à moradia, compreendendo compra e venda, e locação. As abordagens feitas até o presente sobre o seu 
funcionamento detectaram que ele opera a partir de submercados - em cada um dos quais atuam apenas dois agentes (compradores e vendedores ou locadores e inquilinos) - e se caracteriza, inevitavelmente, por nexos ou relações interpessoais. Trata-se de uma das propriedades que diferenciam o mercado imobiliário em áreas pobres do mercado formal.

Por sua vez, o mercado de compra e venda e o de aluguel em áreas pobres são detentores de distintas propriedades: enquanto no de compra e venda, as relações tendem a não mais existir após a finalização do pagamento, no de aluguel, as relações perduram ao longo de toda a vigência da locação, gerando uma aproximação maior de locadores e inquilinos.

Essa qualidade repercute na fixação dos preços de aluguel, na medida em que as transações são realizadas "olho no olho", encerrando algo de "indecifrável", ao esconder processos de interpretação e julgamento por parte dos agentes que, dessa forma, ajustam-se à situação. É por isso que se inviabiliza uma análise econométrica dos preços nesse mercado. Significa isso que as relações interpessoais - como princípio universal de funcionamento do mercado imobiliário em áreas pobres - criam as condições necessárias que marcam as singularidades de funcionamento de cada um dos submercados, singularidades fortemente dependentes da situação de cada um deles.

Ademais, essas relações fundamentam-se na convenção confiançalealdade, responsável, em última instância, pela a coordenação do MIAP, quando há ausência de instituições que funcionem como "fiadoras". Tratase de mais uma particularidade - identificada em algumas metrópoles, como na do Recife - que torna possível a emergência das singularidades presentes em cada um dos submercados.

Tais singularidades devem ser desnudadas a fim de servirem de subsídio à formulação de políticas de regularização fundiária. Essas não devem minimizar o fato de a introdução de outro agente - como instância do poder público, no caso, o município - alterar a coordenação desse mercado, de modo a correr-se o risco de redundar em favorecimento aos inquilinos, o que é justo e devido, mas em desamparo completo dos locadores. 


\section{MERCADOS IMOBILIÁRIOS EM ÁREAS POBRES: SINGULARIDADES, PARTICULARIDADES E UNIVERSALIDADES}

Resumo: As reflexões sobre o mercado imobiliário em áreas pobres induziram questionarmos se as suas normas gerais de funcionamento não estariam obscurecendo as particularidades e as singularidades observadas em cada um dos submercados, especialmente no de locação, em que as relações interpessoais perduram durante todo o período do aluguel. Frente a essa indagação, este texto tem como objetivo verificar a hipótese de que o mercado imobiliário de locação em áreas pobres funciona a partir de normas gerais, mas também de normas dependentes das situações nas quais eles se inserem. O teste dessa hipótese levou a refletir-se sobre a possibilidade de uma leitura econométrica dos preços realizados, bem como sobre a validade de políticas de regularização fundiária de caráter universal.

Palavras-chave: mercado imobiliário formal, mercado imobiliário informal, áreas pobres.

HOUSING MARKETS IN POOR AREAS: SINGULARITIES, PARTICULARITIES AND UNIVERSALITY.

Abstract: Reflections on the housing market in poor areas led to question whether the general rules for its operation would not be obscuring the particularities and singularities observed in each of the submarkets, especially in the leasing market where the interpersonal relationships persist throughout the rental period. Faced with this question, this paper aims to verify the hypothesis that the rental housing market in poor areas works from general rules as well as from rules that depend on the situations in which they are included. The test of this hypothesis led to reflect on the possibility of an econometric reading of realized prices, as well on the validity of universal land regularization policies.

Keywords: Formal housing market, informal housing market, poor areas. 


\section{BIBLIOGRAFIA}

ABRAMO, P. (2009) A cidade informal COM-FUSA - mercado informal em favelas e a produção da estrutura urbana nas grandes metrópoles latinoamericanas. In: ABRAMO, P. (Org.). Mercado imobiliário informal, a porta de entrada nas favelas brasileiras. Porto Alegre: Antac, p. 49-79.

BATIFOULIER, P.; LARQUIER, G. de. (2006) De la convention e de ses usages. In: BATIFOULIER (Org). Théorie des conventions. Paris: Economica, p. 7-31, 2001.

BARROS FILHO, M. N. M. As múltiplas escalas da diversidade intraurbana: uma análise de padrões socioespaciais no Recife (Brasil). Tese (Doutorado em Desenvolvimento Urbano) - Departamento de Arquitetura e Urbanismo, Universidade Federal de Pernambuco, Recife.

BESSY, C.; FAVEREAU, O. (2003) Instituitions et économie des conventions. Cahiers d'Économie politique, v. 1, no 44, p. 119-164, Disponível em $<$ http://www.cairn.info/article $>$. Acesso em: 12 jun. 2009.

BOLTANSKI, L.; THÉVENOT, L. (1991). De la justification - les économies de la grandeur. Paris: Gallimard.

CHAUÍ, M. 1997. (1997) Convite à filosofia. Editora Ática, São Paulo.

GUARESCHI, P. (1988) Alteridade e relação: uma perspectiva crítica. In: ARRUDA. A. (Org.) Representando a alteridade. Petrópolis, RJ: Vozes, p. 149-161.

LACERDA, N.; MORIM, J. (2009) Mercado imobiliário informal de habitação na Região Metropolitana do Recife. In: ABRAMO, P. (Org.). Mercado imobiliário informal, a porta de entrada nas favelas brasileiras. Porto Alegre: Antac, p.112-139.

LACERDA, N. (1991) La production sociale des intérêts fonciers et immobiliers: le cas de Recife (Brésil). Tese de doutorado, Université Sorbonne Nouvelle.

(2011) Mercado imobiliário de aluguel em áreas pobre e Teoria das Convenções. Olinda: Ceci. Disponível em <http://www.cecibr.org/ceci/br/publicacoes/livros.html>

LAHR, C. (1945) Manual de filosofia. Porto: Livraria Apostolado da Imprensa.

THÉVENOT, L. (2006). L'action au pluriel - sociologie des regimes d'engagement. Paris: Éditions la Découverte.

Data de submissão: 28/11/12 - Data de aprovação: 17/01/13 